\title{
Towns with extremely low mortality due to ischemic heart disease in Spain
}

\author{
María José Medrano*, Raquel Boix, Alba Palmera, Rebeca Ramis, Iñaki Galán and Gonzalo López-Abente
}

\begin{abstract}
Background: The cause of coronary disease inframortality in Spain is unknown. The aim of this study is to identify Spanish towns with very low ischemic heart disease mortality, describe their health and social characteristics, and analyze the relationship with a series of contextual factors.

Methods: We obtained the number of deaths registered for each of 8,122 Spanish towns in the periods 1989-1998 and 1999-2003. Expected deaths, standardized mortality ratio (SMR), smoothed Relative Risk (RR), and Posterior Probability (PP) of RR $>1$ were calculated using Bayesian hierarchical models. Inframortality was defined as any town that displayed an RR below the $10^{\text {th }}$ percentile, an SMR of under 1 for both sexes, and a PP of RR $>1$ less than or equal to 0.002 for male and 0.005 for female mortality, during the two periods covered. All the remaining towns, except for those with high mortality classified as "tourist towns", were selected as controls. The association among socioeconomic, health, dietary, lifestyle and vascular risk factors was analyzed using sequential mixed logistic regression models, with province as the random-effects variable.
\end{abstract}

Results: We identified 32 towns in which ischemic heart disease mortality was half the national rate and four times lower than the European Union rate, situated in lightly populated provinces spread across the northern half of Spain, and revealed a surprising pattern of geographic aggegation for 23 of the 32 towns. Variables related with inframortality were: a less aged population (OR $0.93,95 \%$ Cl 0.89-0.99); a contextual dietary pattern marked by a high fish content (OR 2.13,95\% Cl 1.38-3.28) and wine consumption (OR 1.50,95\% Cl 1.08-2.07); and a low prevalence of obesity (OR $0.47,95 \% \mathrm{Cl} 0.22-1.01)$; and, in the case of towns of over 1000 inhabitants, a higher physician-population ratio (OR 3.80, 95\% Cl 1.17-12.3).

Conclusions: Results indicate that dietary and health care factors have an influence on inframortality. The geographical aggregation suggests that other factors with a spatial pattern, e.g., genetic or environmental might also be implicated. These results will have to be confirmed by studies in situ, with objective measurements at an individual level.

Keywords: Ischemic heart disease, Mortality, Spatial analysis, Spain

\section{Background}

Ischemic heart disease mortality in Spain is very low in comparison with other countries in the European region $[1,2]$. Domestic distribution is not uniform, however, so that provinces with lower mortality register rates that are $40 \%$ lower than the national rate [3]. Spanish mortality studies at a municipal level show that coronary mortality displays very wide variability, even after the use of smoothing techniques $[4,5]$. Hence, there are large areas of coronary inframortality in Spain, and

\footnotetext{
* Correspondence: pmedrano@isciii.es

Centro Nacional de Epidemiología, Instituto de Salud Carlos III, Madrid, Spain
}

within these, there are towns whose populations show an extremely low risk of dying from coronary disease.

To our knowledge, no study has previously sought to characterize inframortality due to ischemic heart disease in Spain. Studies that have analyzed the geographical distribution of vascular mortality and other causes of death, have focused on identifying areas with excess mortality $[6,7]$ or been targeted at studying the impact of specific factors, such as social inequalities [8-10] and environmental [11-14] or dietary factors, [15-17] on increased risk of dying. At an international level, what are now regarded as classic ecological studies $[18,19]$

\section{Biomed Central}


drew attention to the lower mortality in southern European countries, but analyses on the Mediterranean paradox and its link to diet and hypercholesterolemia [20-22] used population clusters that were too large and, by extension, too heterogeneous (e.g. country), and failed to take multifactorial and contextual aspects of the disease into account. Many studies have shown that the socioeconomic characteristics of the local setting have an influence on individual cardiovascular risk, even when adjustment is made for individual risk [23].

In the last decade, the development of spatial epidemiology and epidemiology of the social context has generated new theoretical and methodological frameworks, which enable the study of low coronary mortality to be addressed with a new approach of greater potential [24].

This study sought to identify Spanish towns with very low ischemic heart disease mortality, describe their health care and social characteristics, and analyze the relationship with different contextual factors.

\section{Methods}

\section{Mortality}

This study was based on a small-area spatial analysis of mortality, with the study units being Spanin's 8,073 towns as per the 1991 and 2001 Population Censuses [25].

The study analyzed mortality due to ischemic heart disease (codes 410-414 of the International Classification of Diseases $9^{\text {th }}$ Revision (ICD-9) and codes I20-I25 of the ICD-10) corresponding to two periods, 1989-1998 and 1999-2003. Deaths registered at a municipal level, broken down by sex and age, were obtained from individual anonymized files furnished by the National Statistics Institute (Instituto Nacional de Estadistica-INE). Age and sex population data in each of the two periods (1989-1998 and 1999-2003), were drawn from the 1991 and 2001 census respectively, so changes in population figures and age structure were taken into account in mortality calculations.

The following were calculated for each town, for each of the two periods studied, and for men and women separately: a) expected deaths, using the overall national age- and sex-specific rates as reference; b) standardized mortality ratio (SMR); and c) smoothed Relative Risk (RR) and Posterior Probability (PP) of RR $>1$, using the Besag, York and Mollié hierarchical model fitted using Markov chain Monte Carlo simulation methods [26]. The spatial distribution of the RRs was plotted on maps using geographic information systems.

\section{Definition of inframortality}

The criteria used to define ischemic heart disease inframortality were: a) a smoothed Relative Risk below the $10^{\text {th }}$ percentile of the distribution of municipal coronary mortality nationwide; b) an SMR of less than 1 in both sexes; and c) a Posterior Probability of RR $>1$ less than or equal to 0.002 for male and 0.005 for female mortality (due to the lower number of deaths registered). Towns that met these three criteria in the two target periods were identified and then selected separately for each sex to ensure representation of female inframortality. A total of 32 towns were selected.

The remaining towns in Spain $(\mathrm{n} 7,953)$ were taken as controls, with high-mortality towns classified as "tourist towns" by the National Statistics Institute in the 2008 Hotel Occupation Survey [27] (88 towns) being excluded to avoid possible errors of classification of the variable "residence", and/or imported mortality [28].

\section{Characteristics studied}

\section{a) Socioeconomic indicators at a municipal level}

Number of inhabitants, percentage of the population over the age of 65 years, percentage of illiteracy, percentage of unemployment, percentage of the population engaged in farming, and number of inhabitants per province, based in all cases on data provided by the Census [25] (data refer to 2001).

Rurality index [29]. This is a complex indicator that takes the following into account: population density; population aged over 65 years and under 14 years; dependency index; retirement index; population devoted to the primary sector; and habitability of dwellings. It has a rising scale, ranging from -3.50 (minimum rurality) to 3.78 (maximum rurality), with a mean of 0 (data refer to 2001).

Deprivation index [30]. This takes into account the percentages of unemployment, illiteracy and manual workers. It ranges from -3.76 (minimum deprivation) to 5.06 (maximum deprivation), with a mean of 0 (data refer to 2001).

Socioeconomic level [31]. This is drawn up on the basis of occupation and professional status (data refer to 2001).

Level of disposable family income per inhabitant, [32] an estimate based on provincial disposable family income and the following municipal data: telephones installed in private homes; broadband internet; proportion of inhabitants with higher education; proportion of skilled workers; proportion of job seekers; distance to main town in the area; and mean cost of housing. This indicator, available solely for towns of over 1,000 inhabitants, was imputed for towns with smaller populations (n 4,909, total population 1,541,626 inhabitants) using linear regression and the National Statistics Institute's indicator of socioeconomic status (r 0.89) (data refer to 2003)

Industrial index, [32] i.e., town revenue deriving from business tax (Impuesto de Actividades Económicas) 
levied on local industrial activities, divided by the total business-tax revenue for the country as a whole. This indicates the town's relative ranking in national industry and was only available for towns of over 1,000 inhabitants (data refer to 2003).

\section{b) Health-care indicators}

Number of licensed physicians in the province per 1,000 population, [33] hospital beds in the province per 1,000 population, and high-tech resources (hemodynamics and angiography units) per million population [34] (data refer to 2001).

\section{c) Dietary factors}

Composition of the provincial family diet per person per day, [35] based on food purchased for home consumption, in terms of total calories (kilocalories), total fat, fish, folates, olive oil, wine and alcohol (grams)(data refer to 1991).

\section{d) Mortality pattern, longevity, competitive mortality, and quality of certification of cause of death}

SMR of all-cause municipal mortality; mean age at death; mortality due to malignant tumors; and mortality due to ill-defined causes. Deaths registered at a municipal level, broken down by sex and age, were obtained from individual anonymized files furnished by the National Statistics Institute (data refer to 2001).

\section{e) Cardiovascular risk factors}

Provincial age- and sex-adjusted prevalence of arterial hypertension, hypercholesterolemia, obesity, diabetes, leisure-time sedentarism and smoking among the population aged over 20 years [36] (self-reported data refer to 1999).

\section{Statistical analysis}

Variance analysis was used to compare low-mortality towns to the remaining towns by reference to the factors considered. To control for any potential confounding biases stemming from associations among the factors analyzed, mixed-effects logistic regression models were fitted, taking coronary mortality as the dichotomous dependent variable (low-mortality towns versus remaining towns), with province introduced as a random-effects term. The following three sequential logistic models were constructed: the first was adjusted for demographic and socioeconomic factors, taking the socioeconomic index (estimated disposable family income), rather than individual variables, as a complex indicator, in order to obtain models that were more parsimonious; the second was additionally adjusted for dietary variables and prevalence of cardiovascular risk factors estimated at a provincial level; and lastly, the third model was, in turn, additionally adjusted for prevalence of protective dietary factors (consumption of wine and fish) and health-care resources. To prevent overadjustment for redundant data in the case of the variables "total calories" and "wine consumption", the variables "total fat" and "alcohol consumption" were excluded.

\section{Sensitivity analyses}

In view of the fact that mortality rates in small populations can be unstable, even when multi-annual periods are pooled, the analysis was repeated, by restricting it to towns of over 1,000 inhabitants.

In the same manner, the restrictive criteria used to define inframortality make that towns in which there are very few inhabitants and no coronary deaths are not selected because they fail to meet the significance criterion ( $P P$ of $R R>1$ ), so the analysis was also repeated including the 397 towns with zero deaths as inframortality towns, irrespective of their PP of RR > 1 value.

The study was approved by the Research Committee of the Carlos III Institute of Health and complies with the statutory criteria for statistical secrecy, in accordance with the National Statistics Institute's data-release protocol.

\section{Results}

Table 1 shows the population data, location, and ischemic heart disease mortality of the 32 towns selected. The overall number of deaths due to ischemic heart disease in these 32 towns was 443 versus the figure of 850 which would have been expected, had their age-specific mortality been equal to that of Spain as a whole. In 2001, the mortality rates (mean \pm standard deviation, rates per 100,000 population, adjusted to the standard European population) were $43.4 \pm 20.6$ in men and $16.3 \pm 9.6$ in women, notably lower than national rates (91.6 and 39.5, respectively) and those of the 27 European Union countries (153.9 and 78.4, respectively).

These towns were distributed across the northern half of the country, and belonged to the provinces of Burgos (10), Cuenca (5), Cantabria (3), Palencia (3), Teruel (2), Navarre (2), Pontevedra (2), Lugo (1), Orense (1), Tarragona (1), Salamanca (1), Segovia (1) and Soria (1). Only two were situated on the coast (Suances in Cantabria, and Deltebre in Tarragona).

The map plotted in Figure 1 shows that 23 of the 32 towns with inframortality were geographically grouped into four areas, namely: central Galicia (marked in the figure as area 1); provinces of Burgos and Palencia in northern Castille-Leon (area 2); province of Cuenca (area 3); and western Navarre (area 4).

In comparison with the remainder (Table 2), towns with coronary inframortality were located in provinces with low population density ( $p$ 0.023), and had few inhabitants, though the difference vis-à-vis the mean size of the country's remaining towns did not prove statistically significant. Insofar as socioeconomic characteristics were concerned, the towns selected displayed lower 
Table 1 Towns with extremely low mortality due to ischemic heart disease

\begin{tabular}{|c|c|c|c|c|c|c|c|c|c|c|}
\hline \multirow[t]{3}{*}{ ARs/TOWN } & \multirow[t]{3}{*}{ PROVINCE } & \multirow[t]{3}{*}{ POPULATION } & \multicolumn{8}{|c|}{ MORTALITY 1999-2003 } \\
\hline & & & \multicolumn{3}{|c|}{ MEN } & & \multicolumn{4}{|c|}{ WOMEN } \\
\hline & & & RATE* & SMR & RR & PP & RATE & SMR & RR & PP \\
\hline \multicolumn{11}{|l|}{ Castile-León } \\
\hline Aranda de Duero & Burgos & 30,875 & 63.7 & 0.70 & 0.68 & 0.0000 & 23.4 & 0.57 & 0.57 & 0.0002 \\
\hline Salas de los Infantes & Burgos & 2,085 & 18.7 & 0.21 & 0.56 & 0.0018 & 19.7 & 0.48 & 0.58 & 0.0106 \\
\hline Estepar & Burgos & 797 & 20.8 & 0.23 & 0.62 & 0.0008 & 0.0 & 0.00 & 0.53 & 0.0018 \\
\hline Balbases (Los) & Burgos & 341 & 0.0 & 0.00 & 0.63 & 0.0036 & 34.3 & 0.84 & 0.57 & 0.0050 \\
\hline Castrojeriz & Burgos & 971 & 70.8 & 0.78 & 0.69 & 0.0038 & 8.3 & 0.22 & 0.53 & 0.0006 \\
\hline Pampliega & Burgos & 394 & 0.0 & 0.00 & 0.61 & 0.0034 & 0.0 & 0.00 & 0.53 & 0.0042 \\
\hline Santa Maria del Campo & Burgos & 710 & 66.7 & 0.74 & 0.65 & 0.0038 & 31.9 & 0.78 & 0.57 & 0.0042 \\
\hline Villadiego & Burgos & 1,924 & 51.5 & 0.46 & 0.66 & 0.0032 & 48.8 & 0.60 & 0.57 & 0.0038 \\
\hline Villahoz & Burgos & 402 & 69.0 & 0.76 & 0.65 & 0.0090 & 0.0 & 0.00 & 0.54 & 0.0040 \\
\hline Merindad de Río Ubierna & Burgos & 1,330 & 45.5 & 0.50 & 0.66 & 0.0026 & 9.4 & 0.23 & 0.58 & 0.0038 \\
\hline Aguilar de Campoo & Palencia & 7,435 & 55.1 & 0.61 & 0.70 & 0.0026 & 17.1 & 0.42 & 0.52 & 0.0000 \\
\hline Alar del Rey & Palencia & 1,223 & 40.4 & 0.45 & 0.71 & 0.0200 & 13.1 & 0.32 & 0.54 & 0.0018 \\
\hline Cervera de Pisuerga & Palencia & 2,586 & 60.0 & 0.66 & 0.77 & 0.0334 & 17.5 & 0.43 & 0.58 & 0.0022 \\
\hline Aldeadavila de la Ribera & Salamanca & 1,540 & 63.5 & 0.70 & 0.65 & 0.0150 & 12.8 & 0.31 & 0.50 & 0.0034 \\
\hline San Pedro de Gaillos & Segovia & 337 & 55.8 & 0.62 & 0.67 & 0.0088 & 0.0 & 0.00 & 0.56 & 0.0042 \\
\hline Berlanga de Duero & Soria & 1,100 & 61.5 & 0.68 & 0.75 & 0.0296 & 20.3 & 0.49 & 0.60 & 0.0048 \\
\hline \multicolumn{11}{|l|}{ Castile-La Mancha } \\
\hline Palomares del Campo & Cuenca & 928 & 0.0 & 0.00 & 0.60 & 0.0012 & 11.6 & 0.28 & 0.60 & 0.0100 \\
\hline Torrejoncillo del Rey & Cuenca & 652 & 30.2 & 0.33 & 0.61 & 0.0008 & 25.7 & 0.63 & 0.62 & 0.0128 \\
\hline Sotorribas & Cuenca & 955 & 12.6 & 0.14 & 0.62 & 0.0020 & 9.6 & 0.23 & 0.56 & 0.0030 \\
\hline Quintanar del Rey & Cuenca & 7,254 & 50.3 & 0.56 & 0.65 & 0.0016 & 35.2 & 0.86 & 0.79 & 0.0992 \\
\hline \multicolumn{11}{|l|}{ Aragon } \\
\hline Albarracín & Teruel & 1,025 & 62.9 & 0.69 & 0.65 & 0.0004 & 20.9 & 0.51 & 0.64 & 0.0096 \\
\hline Monreal del Campo & Teruel & 2,391 & 30.8 & 0.34 & 0.61 & 0.0012 & 21.7 & 0.53 & 0.61 & 0.0102 \\
\hline \multicolumn{11}{|l|}{ Galicia } \\
\hline Barco de Valdeorras & Orense & 13,518 & 51.7 & 0.57 & 0.65 & 0.0002 & 29.0 & 0.71 & 0.70 & 0.0180 \\
\hline Saviñao (O) & Lugo & 5,010 & 42.5 & 0.47 & 0.66 & 0.0010 & 18.5 & 0.45 & 0.58 & 0.0004 \\
\hline Covelo (O) & Pontevedra & 3,743 & 44.1 & 0.49 & 0.76 & 0.0332 & 18.6 & 0.45 & 0.62 & 0.0024 \\
\hline Lalin & Pontevedra & 19,869 & 58.0 & 0.63 & 0.70 & 0.0004 & 21.0 & 0.51 & 0.62 & 0.0000 \\
\hline \multicolumn{11}{|l|}{ Catalonia } \\
\hline Deltebre & Tarragona & 10,757 & 38.9 & 0.43 & 0.60 & 0.0000 & 15.2 & 0.37 & 0.60 & 0.0028 \\
\hline \multicolumn{11}{|l|}{ Cantabria } \\
\hline Campoo de Enmedio & Cantabria & 3,928 & 46.0 & 0.51 & 0.65 & 0.0018 & 13.1 & 0.32 & 0.54 & 0.0006 \\
\hline Suances & Cantabria & 6,573 & 65.4 & 0.72 & 0.73 & 0.0320 & 21.2 & 0.52 & 0.56 & 0.0024 \\
\hline Valderredible & Cantabria & 1,120 & 46.03 & 0.51 & 0.68 & 0.0050 & 12.5 & 0.31 & 0.54 & 0.0014 \\
\hline \multicolumn{11}{|l|}{ Navarre } \\
\hline Puente La Reina & Navarre & 2,412 & 28.4 & 0.31 & 0.81 & 0.0898 & 7.6 & 0.19 & 0.58 & 0.0050 \\
\hline Yerri & Navarre & 1,543 & 48.2 & 0.53 & 0.81 & 0.0898 & 7.6 & 0.19 & 0.56 & 0.0040 \\
\hline
\end{tabular}

* Rate adjusted according to the standard European population

ARs: Autonomous Regions

SMR: Standardized Mortality Ratio

RR: Relative Risk

PP: Posterior Probability of RR $>1$

proportions of illiteracy, unemployment, aged population, population engaged in farming, and deprivation index, and a higher socioeconomic index of disposable family income. These differences were small, however, and failed to reach statistical significance, with the exception of the lower proportion of the economically active population devoted to farming (28.5\% versus $36.0 \%$, p 0.046), and with marginal statistical significance, the smaller proportion of unemployed population (11.6\% versus 15.4, p 0.066). 


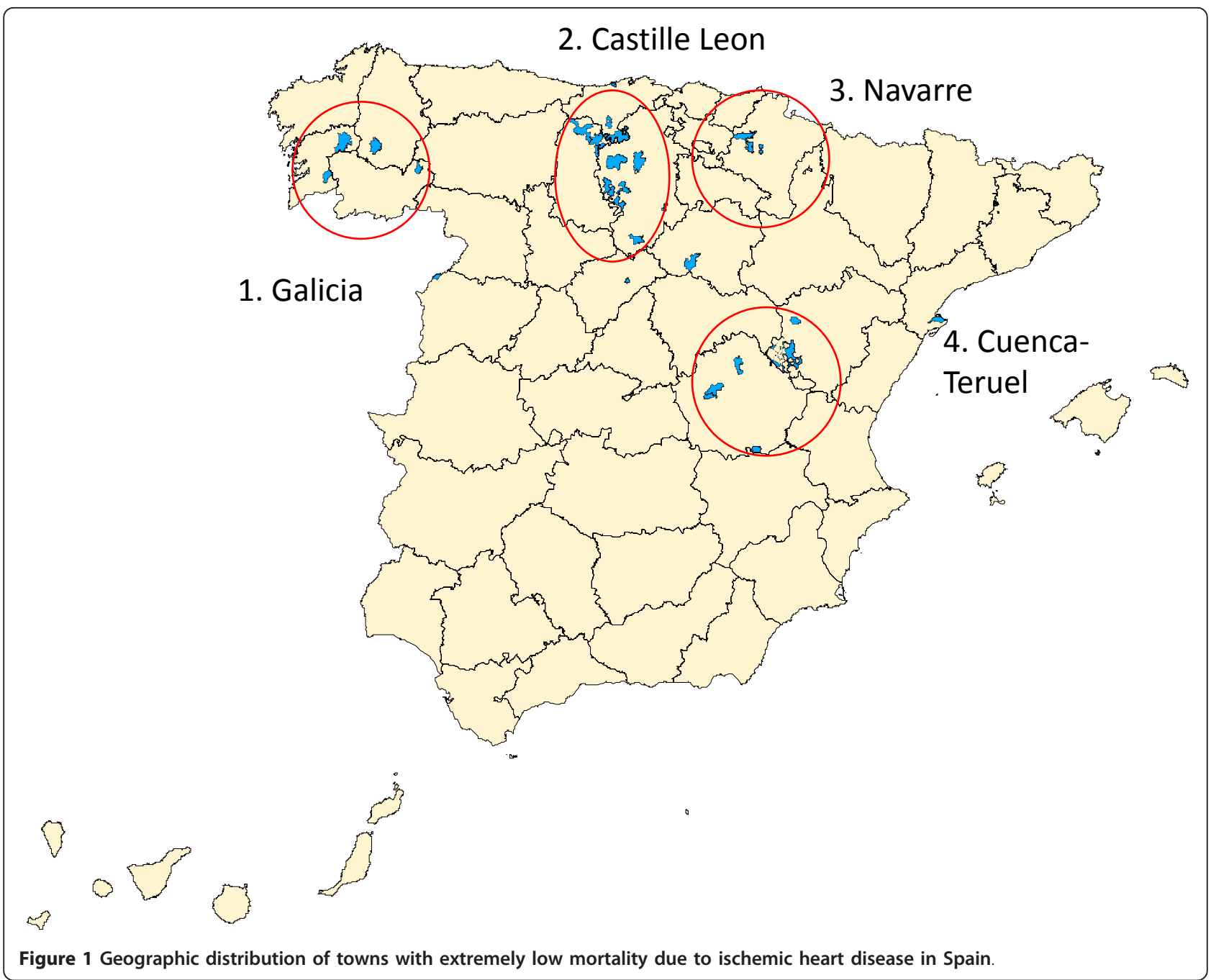

The dietary pattern of the geographic setting of these towns was characterized by a calorie content that was slightly higher than the mean. Fish and wine consumption was much higher in towns with inframortality, $23.6 \%$ and $40 \%$ respectively ( $<<0.001)$, as was that of alcohol in general $(27.8 \% \mathrm{p}<0.001)$. Although the prevalences of smoking, sedentarism, obesity and diabetes were significantly lower than those of controls from a statistical standpoint, the difference was small (1\%). No differences were observed in the prevalence of perceived arterial hypertension and hypercholesterolemia.

All-cause and tumor-related mortality were $20 \%$ lower than the national standard and equal to the mean SMR of the remaining towns. Longevity was longer by 2 years in such towns. Furthermore, the physician-population ratio was equal to and the hospital bed-population ratio was higher than that of control towns, and mortality due to ill-defined causes was $70 \%$ lower than the national standard.
Of the factors considered, those that went furthest to explain municipal inframortality (Table 3 ) were, at a local level, the lower proportion of the population aged 65 years and over, and at a provincial level, the lower prevalence of obesity and the higher consumption of wine and, in particular, fish. No significant associations were found with the frequencies of arterial hypertension, hypercholesterolemia or smoking. Paradoxically, frequency of leisure-time sedentarism was positively associated with coronary inframortality. The fitting sequence showed that the absence of association of some risk factors in model 2 was caused by confounding due to the effect of the protective factors.

The results of the two sensitivity analyses conducted are presented in Table 4. First, the analysis was repeated, solely considering towns of over 1000 inhabitants (Analysis I) and adding indicators, such as the industrial index, which were exclusively available for this group of towns. The results were similar but the 
Table 2 Characteristics in towns with coronary inframortality compared with the country's remaining towns

\begin{tabular}{|c|c|c|c|c|c|}
\hline & \multicolumn{2}{|c|}{$\begin{array}{l}\text { TOWNS WITH CORONARY INFRAMORTALITY } \\
\qquad(\mathrm{n}=32)\end{array}$} & \multicolumn{3}{|c|}{$\begin{array}{l}\text { REMAINING TOWNS } \\
\qquad(\mathrm{n}=7953)\end{array}$} \\
\hline & Mean & SD & Mean & SD & $\mathrm{p}$ \\
\hline Population & 4,164 & 6,357 & 4,541 & 42,266 & 0.960 \\
\hline Provincial population & 359,351 & 200,638 & 826,639 & $1,166,109$ & 0.023 \\
\hline \multicolumn{6}{|l|}{ Socioeconomic indicators * } \\
\hline \% Illiteracy & 2.7 & 3.6 & 3.3 & 3.8 & 0.307 \\
\hline$\%$ Unemployment & 11.6 & 4.3 & 15.4 & 11.7 & 0.066 \\
\hline$\%$ Agriculture & 28.5 & 16.9 & 36.0 & 21.4 & 0.046 \\
\hline$\%$ Population $>=65$ years & 22.7 & 7.3 & 23.5 & 9.5 & 0.635 \\
\hline Rurality index & -0.1 & 0.8 & 0.0 & 1.0 & 0.486 \\
\hline Deprivation index & -0.2 & 0.5 & 0.0 & 1.0 & 0.174 \\
\hline Socioeconomic index & 1.0 & 0.1 & 1.0 & 0.2 & 0.173 \\
\hline Index of disposable family & 5.3 & 1.4 & 4.8 & 2.0 & 0.156 \\
\hline \multicolumn{6}{|l|}{ income } \\
\hline \multicolumn{6}{|l|}{ Health indicators } \\
\hline Licensed physicians per province/1000 & 4.6 & 0.8 & 4.6 & 0.9 & 0.921 \\
\hline Hospital beds per province/1000 & 4.2 & 0.9 & 4.0 & 0.8 & 0.101 \\
\hline Hemodynamic units $/ 10^{6}$ & 0.9 & 1.5 & 2.3 & 2.2 & 0.001 \\
\hline Angiography units $/ 10^{6}$ & 2.3 & 2.1 & 2.6 & 2.5 & 0.450 \\
\hline \multicolumn{6}{|l|}{ Content of diet (gr/person/day) } \\
\hline Total calories, Kcal/per/day & $2,716.0$ & 275.9 & $2,626.5$ & 234.7 & 0.032 \\
\hline Total fat & 34.5 & 6.9 & 33.0 & 7.6 & 0.251 \\
\hline Fish & 93.6 & 21.7 & 75.7 & 14.7 & $<0.001$ \\
\hline Folic acid & 2.8 & 1.6 & 3.3 & 1.4 & 0.060 \\
\hline Olive oil & 34.5 & 6.9 & 33.0 & 7.6 & 0.252 \\
\hline Wine & 101.1 & 57.8 & 72.2 & 40.5 & $<0.001$ \\
\hline Alcohol & 12.4 & 6.2 & 9.7 & 4.3 & $<0.001$ \\
\hline \multicolumn{6}{|l|}{ Prevalence of vascular risk factors** $(\%)$} \\
\hline Arterial hypertension & 20.7 & 2.4 & 20.6 & 2.5 & 0.809 \\
\hline Hypercholesterolemia & 9.1 & 1.3 & 9.4 & 1.6 & 0.216 \\
\hline Obesity & 10.7 & 1.7 & 11.7 & 2.2 & 0.007 \\
\hline Diabetes mellitus & 6.4 & 1.1 & 7.3 & 1.7 & 0.002 \\
\hline Sedentarism & 39.6 & 7.6 & 42.5 & 8.7 & 0.059 \\
\hline Smoking & 27.2 & 2.4 & 28.1 & 2.3 & 0.040 \\
\hline \multicolumn{6}{|c|}{ Pattern of mortality and competitive mortality (SMR) } \\
\hline General mortality men & 0.8 & 0.3 & 0.8 & 0.8 & 0.638 \\
\hline General mortality women & 0.8 & 0.3 & 0.9 & 0.8 & 0.587 \\
\hline Age at death & 77.6 & 15.3 & 75.7 & 15.8 & $<0.001$ \\
\hline Tumor-related mortality & 0.8 & 0.2 & 0.8 & 0.6 & 0.782 \\
\hline III-defined causes of death & 0.3 & 0.2 & 0.3 & 0.4 & 0.692 \\
\hline
\end{tabular}

* Complex socioeconomic indices: see description in Materials and Methods section

**Adjusted for age and sex. Self-reported data.

SD: Standard deviation.

SMR: Standardized Mortality Ratio.

provincial physician-population ratio was strongly associated with municipal inframortality. Second, we conducted a sensitivity analysis modifying the selection criteria to test if selection of these towns affect the results (Analysis II). Although this new analysis was based in a quite different set of towns with different characteristics (ie, small villages with older population and higher income), the main results, namely diet as the factor most associated with low mortality, were basically unchanged.

\section{Discussion}

The cause of inframortality due to ischemic heart disease in southern European countries - arguably their 
Table 3 Factors associated with extremely low coronary mortality.

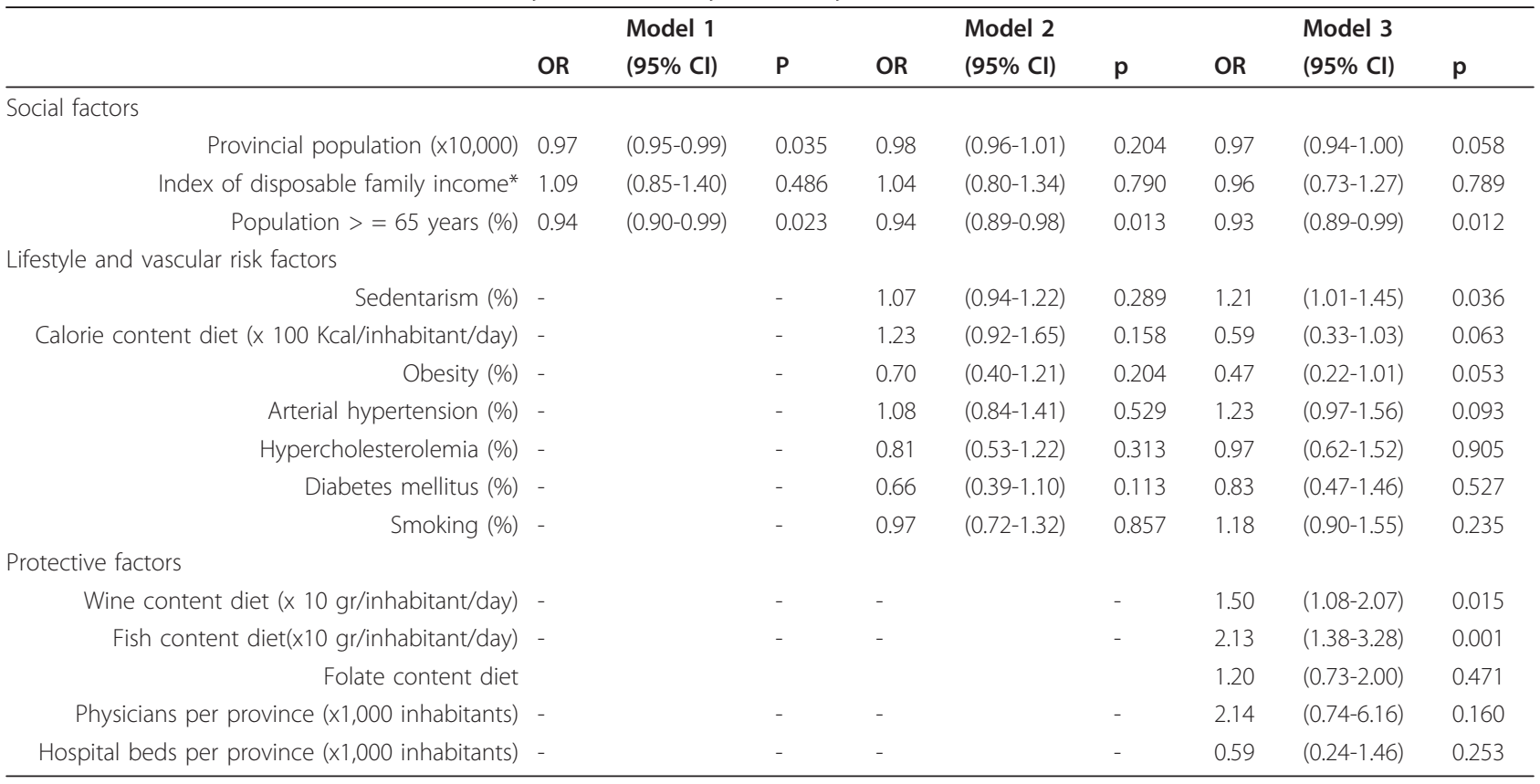

Multivariate analysis (n 7985)

OR: Odds Ratio, derived from mixed-effects logistic regression models, adjusted for:

Model 1: demographic and socioeconomic factors.

Model 2: factors present in model $1+$ diet and prevalence of cardiovascular risk factors.

Model 3: factors present in model 2 + protective factors in the diet and health care resources.

*Index of disposable family income: see description in Methods section

Table 4 Sensitivity analyses.

\begin{tabular}{|c|c|c|c|c|c|c|}
\hline & \multicolumn{3}{|c|}{ Sensitivity analysis I } & \multicolumn{3}{|c|}{ Sensitivity analysis II } \\
\hline & OR & $(95 \% \mathrm{Cl})$ & $\mathbf{p}$ & OR & $(95 \% \mathrm{Cl})$ & $\mathrm{p}$ \\
\hline \multicolumn{7}{|l|}{ Social factors } \\
\hline Provincial population $(\times 10,000)$ & 0.95 & $(0.92-0.98)$ & 0.005 & 0.99 & $(0.99-1.00)$ & 0.006 \\
\hline Index of disposable family income ${ }^{*}$ & 1.18 & $(0.75-1.86)$ & 0.463 & 1.19 & $(1.11-1.28)$ & $<0.001$ \\
\hline Population > = 65 years (\%) & 1.06 & $(0.97-1.15)$ & 0.166 & 1.03 & $(1.02-1.04)$ & $<0.001$ \\
\hline Industrial Index ${ }^{* *}$ & 1.00 & $0.34-3.41$ & 0.670 & - & - & - \\
\hline \multicolumn{7}{|l|}{ Lifestyle and vascular risk factors } \\
\hline Sedentarism (\%) & 1.15 & $(0.95-1.38)$ & 0.150 & 1.00 & $(0.96-1.05)$ & 0.700 \\
\hline Calorie content diet (x $100 \mathrm{Kcal} /$ inhabitant/day) & 0.60 & $(0.32-1.11)$ & 0.108 & 0.82 & $(0.72-0.95)$ & 0.008 \\
\hline Obesity (\%) & 0.64 & $(0.27-1.49)$ & 0.303 & 0.70 & $(0.57-0.85)$ & $<0.001$ \\
\hline Arterial hypertension (\%) & 1.12 & $(0.81-1.53)$ & 0.491 & 1.08 & $(0.98-1.18)$ & 0.113 \\
\hline Hypercholesterolemia (\%) & 1.08 & $(0.64-1.80)$ & 0.782 & 1.03 & $(0.90-1.19)$ & 0.638 \\
\hline Diabetes mellitus (\%) & 1.19 & $(0.65-2.19)$ & 0.567 & 0.87 & $(0.73-1.04)$ & 0.140 \\
\hline Smoking (\%) & 1.06 & $(0.78-1.45)$ & 0.702 & 1.11 & $(0.90-1.55)$ & 0.235 \\
\hline \multicolumn{7}{|l|}{ Protective factors } \\
\hline Wine content diet (x $10 \mathrm{gr} /$ inhabitant/day) & 1.31 & $(0.93-1.84)$ & 0.120 & 1.02 & $(0.94-1.12)$ & 0.531 \\
\hline Fish content $\operatorname{diet}(\times 10 \mathrm{gr} / \mathrm{inh} a b i t a n t / d a y)$ & 2.30 & $(1.44-3.68)$ & $<0.001$ & 1.39 & $(1.16-1.66)$ & $<0.001$ \\
\hline Folate content diet & 0.98 & $(0.54-1.76)$ & 0.940 & 1.35 & $(1.15-1.60)$ & $<0.001$ \\
\hline Physicians per province ( $\times 1,000$ inhabitants) & 3.80 & $(1.17-12.3)$ & 0.026 & 0.90 & $(0.65-1.25)$ & 0.546 \\
\hline Hospital beds per province ( $\times 1,000$ inhabitants) & 1.08 & $(0.34-3.41)$ & 0.894 & 0.87 & $(0.65-1.15)$ & 0.346 \\
\hline
\end{tabular}

Factors associated with extremely low coronary mortality. Analysis I: multivariate analysis confined to towns of over 1,000 inhabitants ( $\mathrm{n}$,074). Analysis II: multivariate analysis with alternative definition criteria, including towns with zero deaths (n 397) as inframortality towns

OR: Odds Ratio, derived from mixed-effects logistic regression models, adjusted for variables in the table.

* Index of disposable family income: see description in Methods section

** Industrial index only available for towns over 1,000 inhabitants. See description in Methods section 
most relevant epidemiological characteristic- is unknown. Thanks to currently available spatial techniques of analysis, this study was able to identify populations that displayed this characteristic in the extreme and maintained it over a period of 15 years. Such identification is of multifold interest, inasmuch as it enables scientific hypotheses to be generated, pinpoints a proposed site for future studies, and corroborates the relationship between ischemic heart disease mortality and the characteristics of the social context.

The results suggest that coronary inframortality in the towns selected, half the national rate and as much as 5 times lower than the rate of northern European countries, [1] is not attributable to underdiagnosis resulting from lack of health care resources, poor quality in the certification of cause of death, or competitive mortality because mortality due to other causes, and to cancer in particular, is likewise low. The greater longevity of the inhabitants of these towns serves to further support the fact that coronary inframortality is real, since there is practically no possibility of there being an unregistered death in Spain. It also implies that these populations exhibit a low risk of dying for any cause, fact that may be explained by many vascular risk and protective factors being common to other diseases, in fact the most frequent ones, such as cerebrovascular disease and cancer

Geographically, these towns with extremely low ischemic heart disease mortality are situated in sparsely populated provinces in the northern half of the country and, unexpectedly, reveal a trend towards geographical aggregation. Although the towns identified are located within the large areas of low mortality shown on official atlases $[4,5]$ and the methods used favor the appearance of geographical aggegations, the possibility cannot be ruled out that grouping may be due to the presence of factors with a spatial pattern -whether of a protective nature or entailing lower exposure to risk factors- which were not taken into account in the analysis. Hence, certain environmental factors (such as climatic factors, composition of the local drinking-water supply or environmental pollution) could not be considered, since these data were unavailable for many towns in the country, including many of the towns identified. Similarly, genetic factors could not be considered and, while genetic population studies undertaken in Spain show that the Spanish population is homogeneous in terms of overall genetic structure, fine structure analyses nevertheless reveal a geographic variation that may be more evident in small, rural or isolated samples [37]. Consequently, one cannot rule out the possibility that, in the case grouping of small towns, there may be some genetic characteristic which confers low vascular risk. One example of a town having low mortality attributable to genetic features is Limone sul Garda, a small town in the north of Italy, whose inhabitants present with a mutation in the apolipoprotein A1 (ApoA1), which confers cardiovascular protection and increases longevity $[38,39]$. Taking all together, the results indicate that further in-depth studies of this spatial agregation are needed.

With respect to the characterization of these towns, when compared to the rest of the country, inframortality was linked to their having: a less aged population structure; a contextual dietary pattern characterized by a higher fish and wine content, lower calorie content and a lower prevalence of obesity; and, in towns of over 1,000 inhabitants, a higher physician-population ratio. In line with the results of earlier studies on social inequalities and health in Spain, [40-42] the strength of association between economic level and coronary inframortality decreased when adjustment was made for diet and vascular risk factors, a finding which might be interpreted as indicating that the latter are intermediate factors and a possible explanation for this association [43]. Nevertheless, the difference in income between these and the remaining towns is small: in other words, they are towns with an income level which, albeit higher, is not excessively so.

Low prevalence of obesity and high consumption of fish appear as the variables most closely associated with coronary inframortality. The effect of both of these on risk of coronary disease has been clearly demonstrated in prospective population studies conducted in a number of countries $[44,45]$ and is also reflected at a population-cluster level in ecologic studies [46]. In Spain, fish consumption is very high in comparison with other western countries, with the communities of Cantabria and Castile-León registering the highest intake [35]. The high mortality of some Spanish provinces has already been associated with lower fish consumption by previous studies [17]. Insofar as obesity is concerned, the result is coherent with recent studies, which reckon that, in the Spanish population, risk of ischemic heart disease attributable to excessive weight can be assumed to be very high and even higher than that posed by the classic risk factors $[47,48]$. While mean calorie intake per person per day was somewhat higher $(90 \mathrm{Kcal})$ in towns with inframortality than in the remaining towns, this difference might nevertheless be accounted for by a higher wine consumption. Indeed, the adjusted results show an inverse association between calorie intake and inframortality. Consumption of wine also showed an association with coronary inframortality, in agreement with many studies that have reported the protective effect of moderate wine consumption $[17,49,50]$. The positive association between leisure-time sedentarism and inframortality is paradoxical and can only be 
interpreted by uncontrolled confounding, e.g., due to physical exercise during the work day.

The explanation for the low coronary mortality of these towns does not lie in differences in the prevalence of arterial hypertension and hypercholesterolemia or diabetes. This may be real or, alternatively, it may be an artifact, due to the data having been drawn from a survey [36] and the fact that the prevalence reported is perceived, i.e., diagnosed and possibly treated. Similarly, these towns' low coronary mortality is not explained by differences in the prevalence of smoking.

Lastly, not only are the health care resources of towns with coronary inframortality no greater than those of the rest of the towns, but they actually have fewer hightech resources, since such resources have been placed in high mortality areas. Nevertheless, when adjustment was made for the remaining factors and the analysis was confined to towns with more stable mortality figures, the physician-population ratio was observed to be positively associated with inframortality in towns with over 1,000 inhabitants.

The possibility of results being biased because the restrictive criteria used to define inframortality can be ruled out as sensitivity analysis modifying the selection criteria to include 397 towns in which there were no coronary death for 15 years yieded similar results, namely dietary factors as the factor most associated with low mortality.

The variables analyzed were based on the information available, in some cases incomplete, such as environmental data, or nonexistent, such as genetic data. While obtaining these data for all Spanish towns is not feasible, studying representative population samples of such towns and of other control towns is possible. This study enables future studies to be steered in this direction. Similarly, there is no data at a municipal level on the factors most directly implicated, such as diet or the prevalence of vascular risk factors. In such cases, provincial data were used by way of giving a description of the context in the absence of the pertinent data. The use of multilevel and spatial models minimizes the biases of this approach [51]. Furthermore, in aspects such as diet and its health-related consequences, the context not only determines individual behavior, but also has an influence on cardiovascular risk, even when individual risk is adjusted for $[23,24]$. However, although we used hierarchical regression models with province-specific random intercepts to adjust the association between municipal coronary mortality for between-province differences in any relevant factor, residual confounding induced by within-province variations in cardiovascular risk factors and diet cannot be ruled out. Lastly, the dietary variables, coming from the only nation-wide nutritional study available in Spain, refer to 1991 which is eight years before the beginning of the study period, and can be temporarily inadequate to mortality data. Nevertheless, dietary factors take time to cause coronary disease and to lead to death, so an eight years lag can be regarded as adequate. Moreover, the nutrition data used are not intake measures, but the composition of the dietary pattern in households, which do not change in short time. Despite these considerations, the stength of the dietary associations with low coronary mortality found in this study deserves further investigations with in depth nutritional study.

The fact of that this was an ecologic study is somewhat irrelevant insofar as the aspects relating to causality are concerned, given that in all the factors considered the causal association is clearly established. However, analysis with aggregate data, coupled with the nature of the data used and the lack of possibly relevant information, render it difficult for statistical significance to be achieved in the explanatory analyses.

\section{Conclusions}

In brief, towns with extremely low coronary mortality were identified. While the results show that dietary factors are linked to inframortality, the geographical aggregation suggests that other factors having a spatial pattern which were not taken into account in the analysis, such as genetic or environmental factors, might also be implicated. These results will have to be confirmed in observational studies in situ, with objective measures at an individual level.

\section{Acknowledgements}

This study was funded by research study grant no. PI06/0656 from Spain's Health Research Fund (Fondo de Investigación Sanitaria).

The authors would like to thank Michael Benedict for his help with the English version of the manuscript.

\section{Authors' contributions}

MJM conceived of the study, participated in its design and coordination and helped to draft the manuscript. MJM, AP, RB, RR, and GLA performed the statistical analysis and interpretation of data and prepared the draft manuscript. All authors participated in the design of the study and in critical review of the manuscript. All authors read and approved the final manuscript.

\section{Competing interests}

The authors declare that they have no competing interests.

Received: 3 October 2011 Accepted: 9 March 2012

Published: 9 March 2012

\section{References}

1. Health statistics: Atlas on mortality in the European Union. 2002-2004 Update.[http://ec.europa.eu/eurostat (accesed November 2011)].

2. Instituto Nacional de Estadística: IneBase. Defunciones según la causa de muerte.[http://www.ine.es/], (accessed May 2010).

3. Centro Nacional de Epidemiología, Información Epidemiológica Interactiva: Ariadna: mortalidad por cáncer y otras causas.[http://193.146.50.130/ ariadna.php], (accessed May 2009). 
4. López-Abente G, Ramis R, Pollán M, Aragonés N, Pérez-Gómez B, GómezBarroso D, Carrasco JM, Lope V, García-Pérez J, Boldo E, GarcíaMendizábal MJ: Atlas municipal de mortalidad por cáncer en España 1989-1998. ISCIII; 2007

5. Benach J, Yasui $Y$, Borrell C, Rosa E, Pasarín MI, Benach N, Español E, Martínez JM, Daponte A: Examining geographic patterns of mortality: the atlas of mortality in small areas in Spain (1987-1995). Eur J Public Health 2003, 13:115-123.

6. Benach J, Yasui Y, Martínez JM, Borrell C, Pasarín MI, Daponte A: The geography of the highest mortality areas in Spain: a striking cluster in the southwestern region of the country. Occup Environ Med 2004, 61:280-281.

7. Vergara Duarte M, Benach J, Martínez JM, Buxó Pujolràs M, Yasui Y: Avoidable and non avoidable mortality: geographical distribution in small areas in Spain (1990-2001). Gac Sanit 2009, 23:16-22.

8. Borrell C, Marí-Dell'olmo M, Serral G, Martínez-Beneito M, Gotsens M, MEDEA Members: Inequalities in mortality in small areas of eleven Spanish cities (the multicenter MEDEA project). Health Place 2010, 16:703-711.

9. Ocaña-Riola R, Saurina C, Fernández-Ajuria A, Lertxundi A, SánchezCantalejo C, Sáez M, Ruiz-Ramos M, Barceló MA, March JC, Martínez JM, Daponte A, Benach J: Area deprivation and mortality in the provincial capital cities of Andalusia and Catalonia (Spain). J Epidemiol Community Health 2008, 62:147-152.

10. Benach J, Yasui Y, Borrell C, Sáez M, Pasarin Ml: Material deprivation and leading causes of death by gender: evidence from a nationwide small area study. J Epidemiol Community Health 2001, 55:239-245.

11. Medrano MJ, Boix R, Pastor-Barriuso R, Palau M, Damian J, Ramis R, del Barrio JL, Navas-Acien A: Arsenic in public water supplies and cardiovascular mortality in Spain. Environ Res 2010, 110:448-454, doi:10.1016/j.envres.2009.10.002.

12. García-Pérez J, López-Cima MF, Boldo E, Fernández-Navarro P, Aragonés N, Pollán M, Pérez-Gómez B, López-Abente G: Leukemia-related mortality in towns lying in the vicinity of metal production and processing installations. Environ Int 2010, 36:746-753.

13. García-Pérez J, Pollán M, Boldo E, Pérez-Gómez B, Aragonés N, Lope V Ramis R, Vidal E, López-Abente G: Mortality due to lung, laryngeal and bladder cancer in towns lying in the vicinity of combustion installations. Sci Total Environ 2009, 407:2593-2602.

14. Ramis R, Vidal E, García-Pérez J, Lope V, Aragonés N, Pérez-Gómez B, Pollán M, López-Abente G: Study of non-Hodgkin's lymphoma mortality associated with industrial pollution in Spain, using Poisson models. BMC Publ Health 2009, 9:26.

15. Medrano MJ, Sierra MJ, Almazan J, Olalla MT, López-Abente G: The association of dietary folate, $\mathrm{B}_{12}$ and $\mathrm{B}_{6}$ with cardiovascular mortality in Spain. An ecological analysis. Am J Public Health 2000, 90:1636-1638.

16. Rodríguez Artalejo F, Guallar-Castillón P, Gutiérrez-Fisac JL, Banegas JR, Rey Calero J: Socioeconomic level, sedentary lifestyle, and wine consumption as possible explanations for geographic distribution of cerebrovascular disease mortality in Spain. Stroke 1997, 28:922-928.

17. Rodríguez Artalejo F, Banegas JR, García Colmenero C, Rey Calero J: Lower Consumption of Wine and Fish as a Possible Explanation for Higher Ischaemic Heart Disease Mortality in Spain's Mediterranean Region Int. J Epidemiol 1996, 25:1196-1201.

18. Keys A: Seven Countries: A Multivariate Analysis of Death and Coronary Heart Disease Cambridge: Harvard University Press; 1980.

19. Cardiovascular Disease Epidemiology. From Aetiology to Public Health. Edited by: Marmot MG, Elliot P. Oxford: Oxford University Press; 1992:

20. Trichopoulou A, Lagiou P: Healthy Traditional Mediterranean Diet: An Expression of Culture, History, and Lifestyle. Nut Rev 1997, 55:383-389, doi:10.1111/j.1753-4887.1997.tb01578.x

21. Renaud S, De Lorgeril M: Wine, alcohol, platelets, and the French paradox for coronary heart disease. Lancet 1992, 339:1523-1526.

22. Criqui $\mathrm{MH}$, Ringel $\mathrm{BL}$ : Does diet or alcohol explain the French paradox? Lancet 1994, 344:1719-1723.

23. Diez-Roux AV, Nieto FJ, Muntaner C, Tyroler HA, Comstock GW, Shahar E, Cooper LS, Watson RL, Szklo M: Neighborhood environments and coronary heart disease: a multilevel analysis. Am J Epidemiol 1997 146:48-63.
24. Chaix B: Geographic life environments and coronary heart disease: a literature review, theoretical contributions, methodological updates, and a research agenda. Annu Rev Public Health 2009, 30:81-105.

25. Instituto Nacional de Estadística: IneBase. Censo de Población y viviendas 2001 y 1991.[http://www.ine.es/], (accessed January 2010).

26. Besag J, York J, Mollié A: Bayesian image restoration, with two applications in spatial statistics. Ann Inst Stat Math 1991, 43:1-20, doi:10.1007/BF00116466.

27. Instituto Nacional de Estadística: IneBase. Encuesta de ocupación hotelera 2008.[http://www.ine.es/], (accessed January 2010).

28. Saavedra JM, Bello LM, Nuñez D, Ortega P, Medrano MJ: Mortalidad por enfermedad isquémica del corazón en las Islas Canarias. Errores en la certificación de la variable residencia de los fallecidos en zonas turísticas. Bol Epidemiol Semanal 2001, 9:161-168.

29. Ocaña-Riola R, Sánchez-Cantalejo C: Rurality index for small areas in Spain. Soc Indic Res 2005, 73:247-266, doi:10.1007/s11205-004-0987-3.

30. Sánchez-Cantalejo C, Ocaña-Riola R, Fernández-Ajuria A: Deprivation index for small areas in Spain. Soc Indic Res 2008, 89:259-273, doi:10.1007/ s11205-007-9114-6.

31. Instituto Nacional de Estadística: IneBase. Indicadores sociales de España 2004.[http://www.ine.es/], (accessed January 2010).

32. Servicio de Estudios "la Caixa": Anuario Económico de España 2005.[http:// www.laCaixa.es/estudios], (accessed January 2010).

33. Instituto Nacional de Estadística: IneBase. Estadística de profesionales sanitarios colegiados 2008.[http://www.ine.es/], (accessed January 2010).

34. Ministerio de Sanidad, Política Social e Igualdad: Catálogo Nacional de Hospitales 2001.[http://www.msc.es/], (accessed January 2010).

35. Varela G, Moreiras O, Carbajal A, Campo M: Encuesta de Presupuestos Familiares. Estudio Nacional de Nutrición y Alimentación 1991. Instituto Nacional de Estadística. Madrid; 1995.

36. Instituto Nacional de Estadística: IneBase. Encuesta sobre Discapacidades, Deficiencias y Estado de Salud 1999.[http://www.ine.es/], (accessed May 2009).

37. Gayán J, Galán JJ, González-Pérez A, Sáez ME, Martínez-Larrad MT, Zabena C, Rivero MC, Salinas A, Ramírez-Lorca R, Morón FJ, Royo JL, Moreno-Rey C, Velasco J, Carrasco JM, Molero E, Ochoa C, Ochoa MD, Gutiérrez M, Reina M, Pascual R, Romo-Astorga A, Susillo-González JL, Vázquez E, Real LM, Ruiz A, Serrano-Ríos M: Genetic structure of the Spanish population. BMC Genomics 2010, 11:326.

38. Gualandri V, Franceschini G, Sirtori CR, et al: A-IMilano apoprotein: identification of the complete kindred and evidence of a dominant genetic transmission. Am J Hum Genet 1985, 37:1083-1097.

39. Sirtori CR, Calabresi L, Franceschini G, Baldassarre D, Amato M, Johansson J, Salvetti M, Monteduro C, Zulli R, Muiesan ML, Agabiti-Rosei M: Cardiovascular status of carriers of the apolipoprotein A-IMilano mutantthe Limone sul Garda study. Circulation 2001, 103:1949-1954.

40. Borrell C, Pasarín MI: The study of social inequalities in health in Spain: where are we? J Epidem Community Health 1999, 53:388-389.

41. Benach J, Daponte A, Borrell C, Artazcoz A, Fernández E: Las desigualdades en la salud y la calidad de vida en España. In El Estado de Bienestar en España. Edited by: Navarro V. Madrid: Tecnos; 2004:.

42. Regidor E, Gutiérrez-Fisac JL, Rodríguez C: Diferencias y desigualdades en salud en España Madrid: Diaz de Santos; 1994.

43. Silhol $R$, Kins $M$, Chauvin $P$, Chaix B: Investigating the spatial variability in incidence of coronary heart disease in the Gazel Cohort: the impact of area socioeconomic position and mediating role of risk factors. $J$ Epidemiol Community Health 2011, 65:137-143, doi:10.1136/jech.2009.087379.

44. Kris-Etherton PM, Harris WS, Appel LJ, For the AHA Nutrition Committee: AHA Scientific Statement. Fish Consumption, Fish Oil, Omega-3 Fatty Acids, and Cardiovascular Disease. Circulation 2002, 106:2747.

45. Poirier P, Giles TD, Bray GA, Hong Y, Stern JS, Pi-Sunyer FX, Eckel RH: Obesity and cardiovascular disease: pathophysiology, evaluation, and effect of weight loss: an update of the 1997 American Heart Association scientific statement on obesity and heart disease from the Obesity Committee of the Council on nutrition, physical activity, and metabolism. Circulation 2006, 113:898-918.

46. Kromann N, Green A: Epidemiological studies in the Upernavik district, Greenland: incidence of some chronic diseases 1950-1974. Acta Med Scand 1980, 208:401-406. 
47. Medrano MJ, Pastor-Barriuso R, Boix R, del Barrio JL, Damián J, Alvarez R, Marín A: Riesgo coronario atribuible a los factores de riesgo cardiovascular en población Española. Rev Esp Cardiol 2007, 60:1250-1256.

48. Brotons C, Soler-Soler J: Obesity, Cinderella of CHD risk factors. Eur Heart $J$ 2000, 21:793-795.

49. Ruidavets JB, Ducimetière $P$, Evans $A$, Montaye $M$, Haas $B$, Bingham A, Yarnell J, Amouyel P, Arveiler D, Kee F, Bongard V, Ferrières J: Patterns of alcohol consumption and ischaemic heart disease in culturally divergent countries: the Prospective Epidemiological Study of Myocardial Infarction (PRIME). BMJ 2010, 341:C5957.

50. Mukamal KJ, Conigrave KM, Mittleman MA, Camargo CA Jr, Stampfer MJ, Willett WC, Rimm EB: Roles of drinking pattern and type of alcohol consumed in coronary heart disease in men. N Engl J Med 2003, 348:109-118.

51. Clayton DG, Bernardinelli L, Montomoli C: Spatial correlation in ecological analysis. Int J Epidemiol 1993, 22:1193-1201.

\section{Pre-publication history}

The pre-publication history for this paper can be accessed here: http://www.biomedcentral.com/1471-2458/12/174/prepub

doi:10.1186/1471-2458-12-174

Cite this article as: Medrano et al: Towns with extremely low mortality due to ischemic heart disease in Spain. BMC Public Health 2012 12:174.

\section{Submit your next manuscript to BioMed Central and take full advantage of:}

- Convenient online submission

- Thorough peer review

- No space constraints or color figure charges

- Immediate publication on acceptance

- Inclusion in PubMed, CAS, Scopus and Google Scholar

- Research which is freely available for redistribution

Submit your manuscript at www.biomedcentral.com/submit 